\section{Kidney \\ Blood Pressure Research}

\title{
A Fast Decline of Residual Renal Function in the First Year is a Predictor for Early Withdrawal from Peritoneal Dialysis in Non-Diabetic Patients
}

\author{
Junni Wang Xishao Xie Xingqun Yan Xin Yang Xiaohui Zhang \\ Jianghua Chen Fei Han
}

Kidney Disease Center, The First Affiliated Hospital, Medical School of Zhejiang University, Hangzhou, China

\section{Key Words}

Residual renal function $\cdot$ Survival $•$ Peritoneal Kt/V urea $•$ Peritoneal dialysis

\begin{abstract}
Background/Aims: Little is known about the relationship between residual renal function (RRF) decline in early period and survival in non-diabetic peritoneal dialysis (PD) patients. Methods: A total of 567 non-diabetic patients who began PD from January 1, 2005 to June 30, 2013 was investigated. The rate of RRF decline was determined by the "slope of the trend equation" of serial RRFs. A composite end-point of all-cause mortality and conversion to hemodialysis (HD) was used, survival status was censored on June 30, 2016. Results: The median of "the slope of RRF decline equation" was $0.308(0.001-2.111) \mathrm{ml} / \mathrm{min} / 1.73 \mathrm{~m} 2 /$ month. In the median follow-up period of 43 months (range 12 to 120 months), 65 (11.5\%) patients died, 90 (15.9\%) patients converted to HD and 171 (30.2\%) patients received kidney transplantation. Multivariate linear regression showed male, high baseline RRF, high baseline peritoneal Kt/ $\mathrm{V}$ urea, low serum albumin and low uric acid were independently associated with the rate of RRF decline in the first year of PD. Multivariate Cox models revealed that RRF decline in the first year remained a predictor for composite end-point $(H R, 2.74,95 \%$ $\mathrm{Cl}, 1.53$ to $4.90, \mathrm{P}=0.001)$. The patients were divided into high RRF decline group $(>0.308 \mathrm{ml} /$ $\mathrm{min} / 1.73 \mathrm{~m} 2 /$ month) and low RRF decline group ( $\leq 0.308 \mathrm{ml} / \mathrm{min} / 1.73 \mathrm{~m} 2 / \mathrm{month})$. In the first three years of PD, the rate of end-point events was higher in high RRF decline group (23.2\%) than that in low RRF decline group $(11.0 \%)(P<0.001)$. There were 189 patients in low RRF decline group and 171 patients in high RRF decline group maintaining PD for more than 3 years, in a median follow-up of 54 months (range 37 to 120 months), the survival rate was $30.9 \%$ in high RRF decline group and $46.4 \%$ in low RRF decline group ( $P=0.883)$. In high
\end{abstract}




\section{Kidney Blood Pressure Research}

RRF decline group, there were 92 patients reaching composited end-point and 112 patients maintaining PD; multivariate Cox model showed high peritoneal Kt/ $\mathrm{V}$ urea after 1 year of PD and high albumin level were protective factors $(\mathrm{HR}, 0.29,95 \% \mathrm{Cl}, 0.13$ to $0.61, \mathrm{P}=0.001$; $\mathrm{HR}$, $0.94,95 \% \mathrm{Cl}, 0.90-0.99, \mathrm{P}=0.022$, respectively), while fast $\mathrm{RRF}$ decline remained risk factor for composite end-point ( $\mathrm{HR}, 3.28,95 \% \mathrm{Cl}, 1.48-7.31, \mathrm{P}=0.004)$. Conclusion: A faster RRF decline in the first year was a predictor for all-cause mortality and conversion to HD in non-diabetic PD patients, mainly in the first three year. For patients with faster RRF decline, increasing PD dose was effective to improve survival.

(C) 2019 The Author(s)

Published by S. Karger AG, Basel

\section{Introduction}

Preservation of residual renal function (RRF) is strongly associated with better survival in both peritoneal dialysis (PD) and hemodialysis (HD) [1, 2]. Evidences from many studies suggest that preservation of RRF is better in PD than HD [3-5]. However, the rate of RRF decline varies among PD patients. Moist LM et al. found that among new PD patients, factors including female, non-white race, diabetes mellitus or congestive heart failure, using angiotensin-converting enzyme inhibitor (ACEI) or calcium channel inhibitor might be related with faster RRF loss [3]. Szeto CC et al. reported that patients with proteinuria, high baseline RRF, or using diuretics would have faster RRF decline [6].

The factors influencing RRF are conflicting among studies [3, 6-8]. It was reported that peritonitis was a risk factor for RRF decline in PD patients [9-11], whereas some other studies did not prove this phenomenon $[12,13]$. Kim JK et al. found that excessive weight gain during the first year was correlated with RRF loss [14], however some other findings did not support this observation $[15,16]$.

Diabetes was proved to be associated with RRF loss [3, 6, 7]. However, little is known about whether RRF decline during the early period has more significant effects on patients' survival or technical survival in non-diabetic PD patients. In this study, we did a longitudinal cohort observation of incident non-diabetic PD patients in our center to determine which factors could predict RRF decline in the first year and quantitatively investigate the impact of RRF decline on non-diabetic patients' survival and technical survival.

\section{Materials and Methods}

\section{Study population}

All incident non-diabetic patients who began PD therapy at the First Affiliated Hospital of Zhejiang University in China from January 1, 2005 to June 30, 2013 were investigated. The exclusion criteria included patients with diabetes, anuria (24-hour urine volumeless than $100 \mathrm{~mL}$ ) at PD start, age below 18 years at PD start, conversion from HD to PD or from renal allograft failure to PD, recovery of renal function after PD and incomplete data for study. This study was performed in accordance with the Declaration of Helsinki and was approved by the Clinical Research Ethics Committee of the FirstAffiliated Hospital of Zhejiang University. All participants provided written informed consents.

\section{Data collection}

Clinical data were collected from our regularly updated electronic records and reviews of the patients' medical and nursing notes. Demographic and clinical data, including gender, age, body mass index (BMI), cause of end stage renal disease (ESRD), mean arterial blood pressure (MAP) and comorbidities (angina, myocardial infarction, cerebrovascular disease, chronic pulmonary disease, diabetes, peripheral vascular disease and malignancy) were collected during the follow-up period. The Charlson comorbidity index (CCI) was calculated according to presence of each comorbidity [17]. The collected biochemical data included very low-density lipoprotein cholesterol (VLDL-C), triglycerides, total cholesterol, high-density lipoprotein cholesterol (HDL-C), low-density lipoprotein cholesterol (LDL-C), hemoglobin, serum albumin, uric acid, 


\section{Kidney \\ Blood Pressure Research}

\begin{tabular}{l}
\hline Kidney Blood Press Res 2019;44:12-21 \\
\hline \begin{tabular}{l|l} 
DOI: 10.1159/000497807 & $\begin{array}{l}\text { @ } 2019 \text { The Author(s). Published by S. Karger AG, Basel } \\
\text { www.karger.com/kbr }\end{array}$ \\
\hline Published online: 22 February 2019
\end{tabular}
\end{tabular}

Wang et al.: Residual Renal Function in Peritoneal Dialysis

phosphates, calcium, alkaline phosphatase (ALP), potassium, C-reactive protein and parathyroid hormone during the follow-up period. Use of angiotensin-converting enzyme inhibitor (ACEI)/ angiotensin receptor blocker (ARB) and diuretics, and episodes of peritonitis in the first year of PD period were also collected during the follow-up period.

The primary outcome was a composite end-point including all-cause mortality and conversion to HD. Survival status was censored on June 30,2016, for the patients who were still on PD therapy at our center. In survival analysis, the censored events included kidney transplantation and loss to follow-up.

\section{Assessment of RRF and dialysis indices}

In the pre-dialysis period, the glomerular filtration rate (GFR) was estimated by the Modification of Diet in Renal Disease (MDRD) equation [18]. In the PD period, RRF was calculated as the mean of urea and creatinine clearance and adjusted for $1.73 \mathrm{~m} 2$ of body surface area from a 24-hour urine collection $[19,20]$. We measured RRF generally at 3- to 6-month intervals in the first year of PD period. RRF was no longer assessed when a patient became anuric. The outcome measure in the study was the rate of RRF decline, determined by the "slope of the trend equation" of serial RRFs, which were checked over time for each patient.

Slope of the trend equation:

$$
\hat{b}=\frac{\sum_{i=1}^{n}\left(x_{i}-\bar{x}\right)\left(y_{i}-\bar{y}\right)}{\sum_{i=1}^{n}\left(x_{i}-\bar{x}\right)^{2}}=\frac{\sum_{i=1}^{n} x_{i} y_{i}-n \bar{x} \bar{y}}{\sum_{i=1}^{n} x_{i}^{2}-n \bar{x}^{2}}
$$

Adequacy of dialysis was determined by renal and peritoneal urea clearance index (Kt/V urea) calculated based on 24-hour dialysate collection using PD Adequacy software (Baxter Healthcare). In the subgroup analysis, the outcome measure was the peritoneal Kt/V urea, determined by the average of peritoneal $\mathrm{Kt} / \mathrm{V}$ urea at all visits after a year of PD period. A standard peritoneal equilibration test was performed to determine the peritoneal transport characteristics.

\section{Statistical analysis}

Continuous variables are presented as means and standard deviations or medians with the range depending on the distribution, and categorical variables are presented as frequencies with percentages. Differences between groups were examined with one-way analysis of variance, Mann-Whitney U tests, or chisquare tests as appropriate. A multivariate linear regression model was used to identify the determinants of RRF decline in Year 1 of PD period.

Survival was analyzed using Kaplan-Meier method, and the groups were compared using a log-rank test. The Cox proportional hazards regression model was used to assess the relationship between RRF decline and composite end-point after adjusting for several groups of covariates. Covariates with $P$-value $<0.1$ in univariate models or for importance of concern were selected for multivariate Cox regression models. The results are expressed as hazard ratio (HR) and $95 \%$ confidence interval $(95 \% \mathrm{CI})$. All statistical analysis was performed using SPSS version 22.0 (SPSS Inc.). A $P<0.05$ was considered statistically significant.

\section{Results}

\section{Patient characteristics}

A total of 973 non-diabetic patients received PD at our center during the study period; 406 patients were excluded, and the remaining 567 patients were included in the final analysis (Fig. 1). Their mean age was $49 \pm 14$ years, $57 \%$ of the patients were male, and the median of "the slope of RRF decline equation" was $0.308(0.001-2.111) \mathrm{ml} / \mathrm{min} / 1.73 \mathrm{~m} 2 / \mathrm{month}$. The baseline (defined as within 1 week before initiation of PD therapy) characteristics of the patients are summarized in Table 1. 


\section{Kidney Blood Pressure Research}

Factors correlating with the rate of $R R F$ decline in year 1 of $P D$ period

After incorporating the covariates with $\mathrm{P}$-value $<0.1$ in univariate models into a multivariate linear regression model (Table 2), the results showed that male, high baseline RRF, high baseline peritoneal Kt/V urea, low serum albumin and low uric acid were independently correlated with a fast RRF decline in the first year of PD.

The effects of RRF decline on composite end-point

The median follow-up period was 43 months (range from 12 to 120 months). During the study period, 65 (11.5\%) patients died, 90 (15.9\%) patients were converted to HD and $171(30.2 \%)$ patients received kidney transplantation.

Table 3 shows the risks of composite endpoint (all-cause mortality and conversion to HD) associated with RRF decline. RRF decline in the first year remained a significant predictor of composite endpoint of all-cause mortality and conversion to HD in both the univariate and the fully adjusted multivariable Cox regression models. The fully adjusted hazard ratios (HRs) for composite end-point associated with $1 \mathrm{ml} / \mathrm{min} / 1.73 \mathrm{~m} 2 / \mathrm{month}$ deterioration of RRF decline in the first year was 2.74 (95\% CI, 1.53 to $4.90, P$ $=0.001$ ).

The patients were divided into the following two groups based on the median RRF decline: low $(\leq 0.308 \mathrm{ml} / \mathrm{min} / 1.73 \mathrm{~m} 2 /$ month) and high $(>0.308 \mathrm{ml} /$ $\mathrm{min} / 1.73 \mathrm{~m} 2 /$ month). The Kaplan-Meier estimates of the patients with different RRF decline in relation to the composite end-point are

Table 1. Demographics and biochemical characteristics. Note: Baseline was defined as within 1 week before initiation of PD therapy. Abbreviations: VLDL-C, very low-density lipoprotein cholesterol; HDL-C, high-density lipoprotein cholesterol; LDL-C, low-density lipoprotein; RRF, residual renal function; BMI, body mass index; Kt/V urea, urea clearance index

\begin{tabular}{lc}
\hline Characteristics & Value \\
\hline Slopes of RRF decline in the first year $\left(\mathrm{ml} / \mathrm{min} / 1.73 \mathrm{~m}^{2} /\right.$ month) & $0.308(0.001-2.111)$ \\
Age (years) & $49 \pm 14$ \\
Male (\%) & 57 \\
Primary chronic Glomerulonephritis (\%) & 75.3 \\
BMI (kg/m ${ }^{2}$ ) & $20.81(13.8-30.2)$ \\
Mean arterial pressure (mmHg) & $109(60-180)$ \\
Charlson comorbidity score & $2(2-32)$ \\
Peritonitis episodes in the first year & $0(0-5)$ \\
Baseline biochemistry & \\
Hemoglobin (g/L) & $82(42-156)$ \\
Albumin (g/L) & $37.44 \pm 5.37$ \\
Uric acid ( $\mu$ mol/L) & $516.49 \pm 130.90$ \\
Calcium (mmol/L) & $2.11(1.26-3.51)$ \\
Phosphate (mmol/L) & $1.76(0.40-3.90)$ \\
Triglycerides (mmol/L) & $1.37(0.23-12.51)$ \\
Total cholesterol (mmol/L) & $4.09(1.77-14.13)$ \\
HDL-C(mmol/L) & $1.04(0.34-2.63)$ \\
LDL-C (mmol/L) & $2.22(0.69-8.77)$ \\
VLDL-C (mmol/L) & $0.75(0.11-3.89)$ \\
Alkaline phosphatase (U/L) & $66(17-528)$ \\
Potassium (mmol/L) & $4.55 \pm 0.72$ \\
Parathyroid hormone (pg/mL) & $303.50(3-2500)$ \\
C-reactive protein (mg/L) & $2.80(0-162)$ \\
Fasting blood-glucose (mmol/L) & $4.57(3.13-18.99)$ \\
Baseline RRF (ml/min/1.73 m²) & $6.35(1.46-16.15)$ \\
Baseline peritoneal KT/V urea & $1.17 \pm 0.42$ \\
\hline
\end{tabular}

Fig. 1. Flow chart of the participants in the study cohort. $\mathrm{PD}$, peritoneal dialysis. HD, hemodialysis.

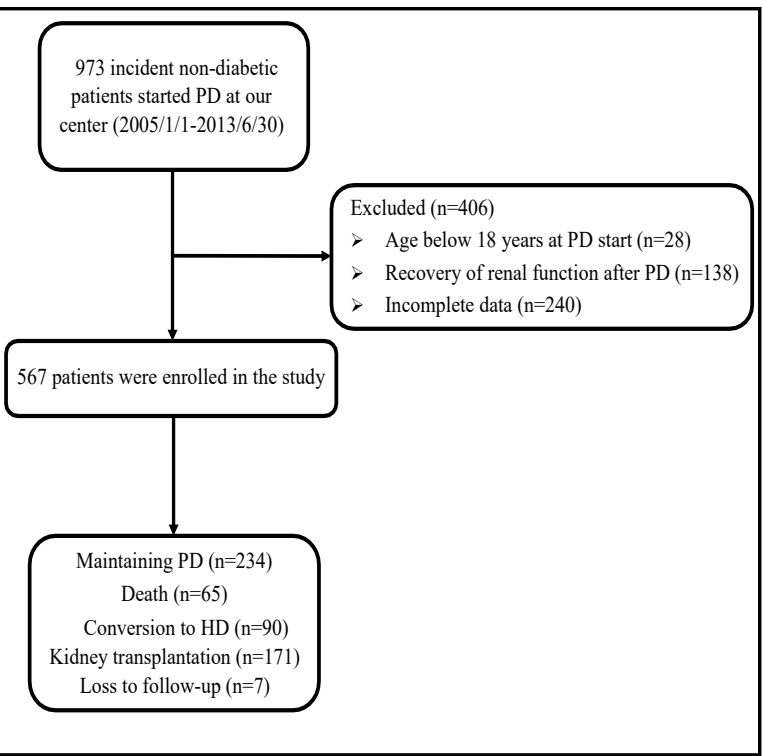




\section{Kidney Bloód Pressure Research}

Table 2. Linear regression analysis of rate of RRF decline in Year 1 of PD period. Abbreviations: VLDL-C, very low-density lipoprotein cholesterol; HDL-C, high-density lipoprotein cholesterol; LDL-C, low-density lipoprotein; RRF, residual renal function; BMI, body mass index; PD, peritoneal dialysis; Kt/V urea, urea clearance index

\begin{tabular}{lcccc}
\hline Factor & $\begin{array}{c}\text { Univariate linear regression } \\
\text { Adjusted regression } \\
\text { coefficient }\end{array}$ & P value & $\begin{array}{c}\text { Multiple linear regression } \\
\text { Adjusted regression } \\
\text { coefficient }\end{array}$ & P value \\
\hline Age & 0.024 & 0.570 & & 0.001 \\
Gender (female versus male) & -0.145 & 0.001 & -0.118 & \\
BMI & -0.055 & 0.192 & & \\
Primary causes & 0.044 & 0.303 & & 0.099 \\
Charlson comorbidity score & 0.066 & 0.118 & & $<.850$ \\
Peritonitis episodes in the first year & 0.017 & 0.683 & & $<0.001$ \\
Mean arterial pressure & -0.074 & 0.080 & -0.056 & 0.554 \\
Hemoglobin & 0.097 & 0.022 & 0.007 & 0.264 \\
Uric acid & -0.183 & $<0.001$ & -0.151 & -0.126 \\
Albumin & -0.178 & $<0.001$ & 0.021 & \\
Calcium & 0.093 & 0.027 & 0.045 & \\
Phosphate & -0.211 & $<0.001$ & & $<0.001$ \\
Triglycerides & 0.003 & 0.936 & & $<0.001$ \\
Total cholesterol & 0.000 & 0.999 & & \\
HDL-C & -0.037 & 0.386 & & \\
LDL-C & 0.008 & 0.849 & & \\
VLDL-C & 0.013 & 0.754 & & \\
Alkaline phosphatase & 0.059 & 0.161 & & \\
Potassium & 0.003 & 0.938 & & \\
Parathyroid hormone & -0.062 & 0.140 & & \\
C-reactive protein & 0.005 & 0.937 & & \\
Fasting blood-glucose & -0.033 & 0.435 & & \\
Baseline RRF & 0.499 & $<0.001$ & & \\
Baseline peritoneal Kt/V urea & 0.105 & 0.013 & & \\
\hline
\end{tabular}

illustrated in Fig. 2. During first three years of PD period, the rate of end-point events was higher in high RRF decline group $(23.2 \%)$ than in low RRF decline group $(11.0 \%)$ (log-rank test $P<0.001$ ). There were 189 patients in low RRF decline group and 171 patients in high RRF decline group maintaining PD for more than 3 years, in a median follow up time of 54 months (range from 37 to 120 months), no significant difference of survival was observed between these two groups after maintaining PD for more than three years (30.9\% in high RRF decline group vs $46.4 \%$ in low RRF decline group, log-rank test $P=0.883$ ).
Table 3. Risks of composite end-point with RRF decline. Note: Composite end-point included all-cause mortality and transfer to hemodialysis. Abbreviations: $\mathrm{CI}$, confidence interval; HR, hazard ratio; RRF, residual renal function. Model 1: Unadjusted, Model 2: Adjusted for age, gender, Model 3: Adjusted for the model 2 covariates and primary causes, Charlson comorbidity score, peritonitis episodes in the first year, Model 4: Adjusted for the model 3 covariates plus serum albumin, phosphate, parathyroid hormone, alkaline phosphatase and baseline RRF

\begin{tabular}{lcc}
\hline Model & HR $(95 \% \mathrm{CI})$ & P Value \\
\hline Model 1 & $3.02(1.91-4.78)$ & $<0.001$ \\
Model 2 & $2.91(1.84-4.62)$ & $<0.001$ \\
Model 3 & $2.77(1.75-4.39)$ & $<0.001$ \\
Model 4 & $2.74(1.53-4.90)$ & $=0.001$ \\
\hline
\end{tabular}




\section{Kidney \\ Blood Pressure Research}

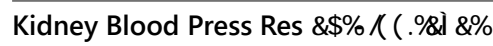

\begin{tabular}{l|l}
\hline DOI: 10.1159/000497807 & (c) 2019 The Author(s). Published by S. Karger AG, Base
\end{tabular}

Published onlıne: 22 February 2019

www.karger.com/kb

The effects of therapies in high decline group after 1 year of $P D$ period on composite end-point

In high RRF decline group, there were 92 patients reaching composited end-point and 112 patients maintaining $\mathrm{PD}$ at the end of follow up. Table 4 shows the comparation of characteristics at 1 year of PD period between patients reaching composite end-point and patients maintaining PD. Patients maintaining PD had younger age, lower peritonitis episodes in the first year, higher serum albumin level and higher peritoneal Kt/V urea after 1 year than patients reaching composite end-point $(P<0.05)$. Patients maintaining PD also had an increased tendency to use ACEI/ARB though it did not reach statistic difference.

After incorporating the covariates with $\mathrm{P}$-value $<0.1$ in Table 4 into a multivariate Cox regression model (Table 5), we showed that in high RRF decline group, high peritoneal Kt/V urea after 1 year of PD period and high albumin level were the protective

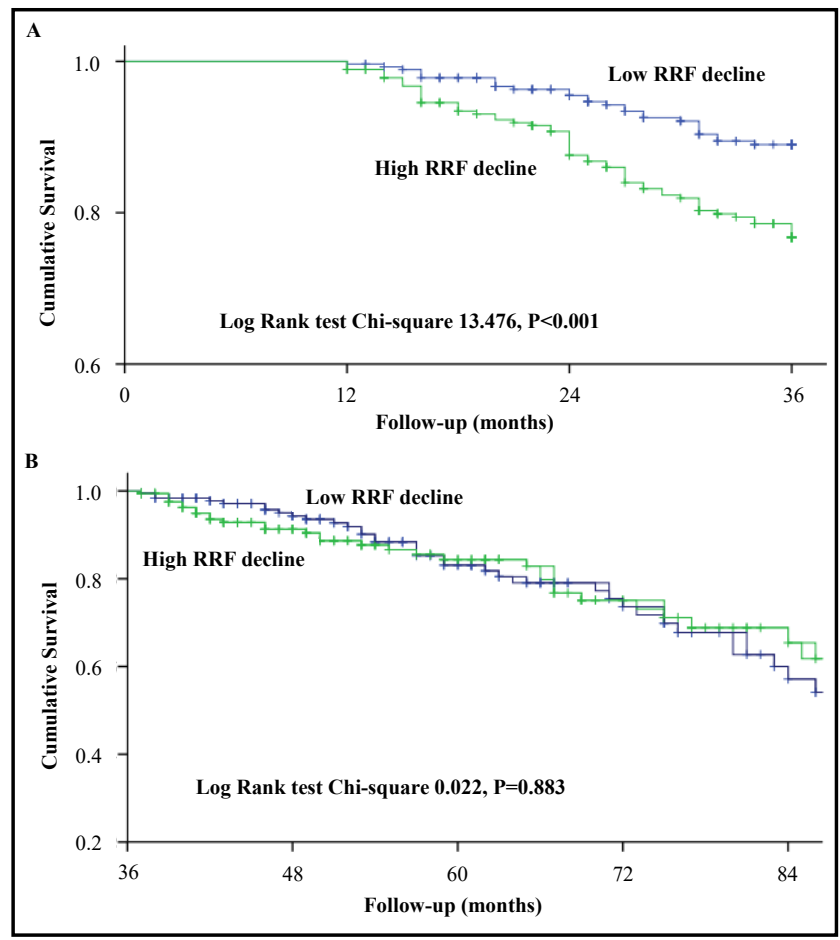

Fig. 2. The Kaplan-Meier estimates of the patients stratified by median of RRF decline in relation to the composite endpoints. Composite end-points included all-cause mortality and conversion to hemodialysis. A. the cumulative survival for both groups of patients in first three years of peritoneal dialysis; B. the cumulative survival for both groups of patients maintaining peritoneal dialysis for more than 3 years. factors (HR, $0.29,95 \% \mathrm{CI}, 0.13$ to $0.61, P=0.001 ; \mathrm{HR}, 0.94,95 \% \mathrm{CI}, 0.90-0.99, \mathrm{P}=0.022$, respectively), while fast $\mathrm{RRF}$ decline remained the risk factor for composite end-point (HR, 3.28, 95\% CI,1.48-7.31, $\mathrm{P}=0.004$ ) .

\section{Discussion}

In this observational study, we found that a fast RRF decline in the first year of PD period was an independent predictor for high risks of all-cause mortality and conversion to HD in non-diabetic PD patients, mainly during the first 3 years of PD period. However, for patients maintaining PD for more than 3 years, RRF decline no longer correlated with the composite end-point (all-cause mortality and conversion to HD). High peritoneal Kt/V urea after 1 year of PD period could be the protective factor for patients with fast RRF decline.

It's important to preserve RRF, even in dialysis patients [21]. The evidences from many studies strongly indicated an association between preservation of RRF and improved patients' survival $[1,2,22-24]$. However, there were many arguments with respect to the factors influencing RRF decline among PD patients. In this study, we found male, high baseline RRF, high baseline peritoneal Kt/V urea, low serum albumin and low uric acid were independently correlated with a fast RRF decline in the first year of PD. An interesting result is that higher serum uric acid level was correlated with lower RRF decline in the first year during PD period. To our knowledge, only a few studies have examined the relationship between serum uric acid level and RRF in PD patients [25, 26]. 


\section{Kidney Blood Pressure Research}

Table 4. Comparation of characteristics at 1 year of PD period of patients reaching composite end-point versus patients maintaining PD in high RRF decline group. Note: Composite end-point included all-cause mortality and transfer to hemodialysis. Abbreviations: RRF, residual renal function; PD, peritoneal dialysis; $\mathrm{Kt} / \mathrm{V}$ urea, urea clearance index

\begin{tabular}{lccc}
\hline Factor & $\begin{array}{c}\text { Patients reaching composite end- } \\
\text { point (92) }\end{array}$ & Patients maintaining PD (112) & $\begin{array}{c}\text { P } \\
\text { value }\end{array}$ \\
\hline The average of peritoneal KT/V urea & $1.38 \pm 0.38$ & $1.55 \pm 0.31$ & 0.001 \\
1 year later & & & 0.069 \\
Medicine & 70.3 & 81.3 & 0.368 \\
$\quad$ ACEI/ARB (\%) & 78.0 & 83.0 & 0.001 \\
$\quad$ Diuretics (\%) & $57 \pm 15$ & $50 \pm 12$ & 0.411 \\
Age (years) & 66.3 & 60.7 & 0.728 \\
Male (\%) & $21.47 \pm 3.08$ & $21.33 \pm 2.65$ & 0.215 \\
BMI (kg/m ${ }^{2}$ ) & $104(50-135)$ & $102(63-136)$ & 0.218 \\
Mean arterial pressure (mmHg) & $2(2-4)$ & $2(2-32)$ & 0.003 \\
Charlson comorbidity score & $0(0-3)$ & $0(0-3)$ & 0.850 \\
Peritonitis episodes in the first year & & & 0.003 \\
Biochemistry & $103 \pm 17$ & $40.8(28.7-48.3)$ & 0.347 \\
Hemoglobin (g/L) & $39.2(25.3-50.6)$ & $404(192-748)$ & 0.617 \\
Albumin (g/L) & $417.5(197-592)$ & $2.32(1.81-2.75)$ & 0.332 \\
Uric acid ( $\mu$ mol/L) & $2.30(1.62-3.05)$ & $1.45(0.71-3.68)$ & 0.427 \\
Calcium (mmol/L) & $1.54(0.49-3.31)$ & $1.54(0.52-11.12)$ & 0.487 \\
Phosphate (mmol/L) & $1.65(0.53-16.62)$ & $4.97(2.76-10.15)$ & 0.613 \\
Triglycerides (mmol/L) & $4.99(2.36-13.37)$ & $1.14(0.71-3.14)$ & 0.695 \\
Total cholesterol (mmol/L) & $1.17(0.52-2.50)$ & $2.57(0.80-5.77)$ & 0.984 \\
HDL-C(mmol/L) & $2.77(0.34-5.48)$ & $0.88(0.10-4.07)$ & 0.078 \\
LDL-C (mmol/L) & $0.94(0.13-8.17)$ & $71(30-300)$ & 0.367 \\
VLDL-C (mmol/L) & $63.5(18-361)$ & $4.12(3.12-6.32)$ & 0.275 \\
Alkaline phosphatase (U/L) & $4.26(2.67-6.59)$ & $2.85(0-66.5)$ & 0.963 \\
Potassium (mmol/L) & $3.08(0-254)$ & $5.15(3.81-11.96)$ & 0.355 \\
C-reactive protein (mg/L) & $5.11(3.59-9.99)$ & $1.31(0-8.02)$ & 0.167 \\
Fasting blood-glucose (mmol/L) & $1.60(0-7.17)$ & $0.45(0.31-1.93)$ & 0.063 \\
RRF (ml/min/1.73 m $\left.{ }^{2}\right)$ & $1.29 \pm 0.48$ & & \\
peritoneal KT/V urea & $0.55(0.31-2.11)$ & & \\
Slopes of RRF decline in the first year & & & \\
(ml/min/1.73 m $\left.{ }^{2} / \mathrm{month}\right)$ & & & \\
\hline
\end{tabular}

In this study, we demonstrated that the faster RRF decline in the first year of PD period was associated with higher risks of all-cause mortality and conversion to $\mathrm{HD}$ in PD patients even after adjusting for several potential confounders (e.g., demographic characteristics, the Charlson comorbidity score, and laboratory parameters) during the first 3 years of PD period. Similar to our results, Maiorca et al. reported a $50 \%$ reduction in mortality in PD patients with RRF [27]. Rocco et al. also reported that for each $10 \mathrm{~L} /$ week/1.73m2 increase in renal Creatinine clearance, there was a $40 \%$ reduced risk for death [28]. A post-analysis of the CANUSA study, which was a multicenter prospective cohort study of 680 incident PD patients in Canada and USA, reported that for each increment of RRF of $5 \mathrm{~L} /$ week/1.73m 2 there was a $12 \%$ reduction in the risk for death and that for each $250 \mathrm{ml}$ increase in urine volume there was a $36 \%$ reduction of risk for death [1]. Different from those studies, we chose two main clinic outcomes including all-cause mortality and conversion to HD as a composite end-point to present the survival status including patients' survival and technical survival in PD. With
Table 5. Multivariate Cox regression of the risk factors for composite end-point in high RRF decline group. Note: Composite endpoint included all-cause mortality and transfer to hemodialysis. Abbreviations: CI, confidence interval; HR, hazard ratio; RRF, residual renal function; Kt/V urea, urea clearance index

\begin{tabular}{lcc}
\hline Factor & HR (95\% CI) & P value \\
\hline Average peritoneal KT/V urea 1 year later & $0.29(0.13-0.61)$ & 0.001 \\
Peritonitis episodes in the first year & $1.35(0.94-1.94)$ & 0.110 \\
Slopes of RRF decline in the first year & $3.28(1.48-7.31)$ & 0.004 \\
ACEI/ARB & $0.68(0.40-1.16)$ & 0.157 \\
Age & $1.01(0.99-1.02)$ & 0.379 \\
Albumin & $0.94(0.90-0.99)$ & 0.022 \\
Alkaline phosphatase & $1.00(0.99-1.00)$ & 0.220 \\
\hline
\end{tabular}




\section{Kidney \\ Blood Pressure Research}

the PD time extending, we found 3 years later, RRF decline no longer affected the composite end-point. Besides, we found that using the "slope of the trend equation" of serial RRFs to observe the dynamic process of RRF decline was more in line with the law of RRF decline. Since high RRF is correlated with reduced inflammatory markers, better solutes clearance, improved nutrition and even improved quality of patients' life [29-33], it may suggest that the preservation of RRF in the early PD period is valuable to improve patients' survival.

In the subgroup analysis, we found the high peritoneal Kt/V urea after 1 year of PD period could be the protective factor for patients with fast RRF decline in the first year of PD period. Similar to our result, in a published study including 1, 677 incident PD patients in America, the PD patients with higher laboratory values for albumin and weekly Kt/Vhad lower mortality but no less conversion from PD to HD therapy in the first year of PD period [34]. Fried L et al. also found Kt/V calculated using actual body weight less than 1.7 in anuric PD patients was associated with increased mortality and more hospitalization [35]. However, a study including 183 PD patients showed the presence and severity of peritoneal calcification were associated with high peritoneal Kt/V [36]. Therefore, it may suggest increasing the PD dose for therapy in fast RRF decline group. Whether high peritoneal Kt/V really benefits would also need to be verified in further prospective studies.

This study has several limitations. First, it was a single-center retrospectivestudy, which only revealed associations but no causation due to its observational nature. Second, only non-diabetic PD patients were included in our study; therefore, it may not be applied to the other dialysis populations. Third, due to the lack of follow-up data, we did not investigate the influence of changes in factors during the observation period on the RRF decline.

\section{Conclusion}

In conclusion, our study revealed that a faster RRF decline in the first year was a predictor for all-cause mortality and conversion to HD in non-diabetic PD patients, mainly in the first three year. For patients with faster RRF decline, increasing PD dose was effective to improve survival.

\section{Acknowledgements}

This study was supported by the funds from National Natural Science Foundation of China $(81570605,81770674)$ and Natural Science Foundation of Zhejiang Province (LY15H050004) to Fei Han.

\section{Disclosure Statement}

The authors declare that no conflicts of interest exist.

\section{References}

1 Bargman JM, Thorpe KE, Churchill DN; CANUSA Peritoneal Dialysis Study Group: Relative contribution of residual renal function and peritoneal clearance to adequacy of dialysis: a reanalysis of the CANUSA study. J Am Soc Nephrol 2001;12:2158-2162.

-2 Obi Y, Rhee CM, Mathew AT, Shah G, Streja E, Brunelli SM, Kovesdy CP, Mehrotra R, Kalantar-Zadeh K: Residual kidney function decline and mortality in incident hemodialysis patients. J Am Soc Nephrol 2016;27:3758-3768. 


\section{Kidney \\ Bloód Pressure Research}

Wang et al.: Residual Renal Function in Peritoneal Dialysis

3 Moist LM, Port FK, Orzol SM, Young EW, Ostbye T, Wolfe RA, Hulbert-Shearon T, Jones CA, Bloembergen WE: Predictors of loss of residual renal function among new dialysis patients. J Am Soc Nephrol 2000;11:556564.

4 Jansen MA, Hart AA, Korevaar JC, Dekker FW, Boeschoten EW, Krediet RT; NECOSAD Study Group: Predictors of the rate of decline of residual renal function in incident dialysis patients. Kidney Int 2002;62:1046-1053.

5 Kjaergaard KD, Peters CD, Jespersen B, Tietze IN, Madsen JK, Pedersen BB, Novosel MK, Laursen KS, Bibby BM, Strandhave C, Jensen JD: Angiotensin blockade and progressive loss of kidney function in hemodialysis patients: A randomized controlled trial. Am J Kidney Dis 2014;64:892-901.

6 Szeto CC, Kwan BC, Chow KM, Chung S, Yu V, Cheng PM, Leung CB, Law MC, Li PK: Predictors of residual renal function decline in patients undergoing continuous ambulatory peritoneal dialysis. Perit Dial Int 2015;35:180-188.

7 Nongnuch A, Assanatham M, Panorchan K, Davenport A: Strategies for preserving residual renal function in peritoneal dialysis patients. Clin Kidney J 2015;8:202-211.

8 Htay H, Cho Y, Pascoe EM, Darssan D, Hawley C, Johnson DW, balANZ trial investigators: Predictors of residual renal function decline in peritoneal dialysis patients: The balANZ Trial. Perit Dial Int 2017;37:283289.

-9 Liao CT, Shiao CC, Huang JW, Hung KY, Chuang HF, Chen YM, Wu KD, Tsai TJ: Predictors of faster decline of residual renal function in taiwanese peritoneal dialysis patients. Perit Dial Int 2008;28:S191-195.

10 Shin SK, Noh H, Kang SW, Seo BJ, Lee IH, Song HY, Choi KH, Ha SK, Lee HY, Han DS: Risk factors influencing the decline of residual renal function in continuous ambulatory peritoneal dialysis patients. Perit Dial Int 1999;19:138-142.

11 Lui SL, Cheng SW, Ng F, Ng SY, Wan KM, Yip T, Tse KC, Lam MF, Lai KN, Lo WK: Cefazolin plus netilmicin versus cefazolin plus ceftazidime for treating CAPD peritonitis: effect on residual renal function. Kidney Int 2005;68:2375-2380.

12 Johnson DW, Mudge DW, Sturtevant JM, Hawley CM, Campbell SB, Isbel NM, Hollett P: Predictors of decline of residual renal function in new peritoneal dialysis patients. Perit Dial Int 2003;23:276-283.

13 Badve SV, Hawley CM, McDonald SP, Brown FG, Boudville NC, Wiggins KJ, Bannister KM, Johnson DW: Use of aminoglycosides for peritoneal dialysis-associated peritonitis does not affect residual renal function. Nephrol Dial Transplant 2012;27:381-387.

14 Kim JK, Kim YS, Song YR, Kim HJ, Kim SG, Moon SJ: Excessive weight gain during the first year of peritoneal dialysis is associated with inflammation, diabetes mellitus, and a rapid decrease in residual renal function. PLoS One 2015;10:e0139033.

15 He L, Liu X, Li Z, Abreu Z, Malavade T, Lok CE, Bargman JM: Rate of decline of residual kidney function before and after the start of peritoneal dialysis. Perit Dial Int 2016;36:334-339.

16 Li L, Liang W, Ye T, Chen Z, Zuo X, Du X, Qian K, Zhang C, Hu X, Li J, Wang L, Ma Z, Yao Y: The association between nutritional markers and biochemical parameters and residual renal function in peritoneal dialysis patients. PLoS One 2016;11:e0156423.

17 Charlson ME, Pompei P, Ales KL, MacKenzie CR: A new method of classifying prognostic comorbidity in longitudinal studies: Development and validation. J Chronic Dis 1987;40:373-383.

18 Levey AS, Bosch JP, Lewis JB, Greene T, Rogers N, Roth D: A more accurate method to estimate glomerular filtration rate from serum creatinine: A new prediction equation. Modification of diet in renal disease study group. Ann Intern Med 1999;130:461-470.

19 van Olden RW, Krediet RT, Struijk DG, Arisz L: Measurement of residual renal function in patients treated with continuous ambulatory peritoneal dialysis. J Am Soc Nephrol 1996;7:745-750.

20 Du Bois D, Du Bois EF: A formula to estimate the approximate surface area if height and weight be known. 1916Nutrition 1989;5:303-311.

21 Krediet RT: How to preserve residual renal function in patients with chronic kidney disease and on dialysis? Nephrol Dial Transplant 2006;21:ii42-46.

22 Termorshuizen F, Korevaar JC, Dekker FW, van Manen JG, Boeschoten EW, Krediet RT; NECOSAD Study Group: The relative importance of residual renal function compared with peritoneal clearance for patient survival and quality of life: an analysis of the Netherlands Cooperative Study on the Adequacy of Dialysis (NECOSAD )-2 Am J Kidney Dis 2003;41:1293-1302. 


\section{Kidney \\ Blood Pressure Research}

\begin{tabular}{|c|c|}
\hline $\begin{array}{l}\text { DOI: } 10.1159 / 000497807 \\
\text { Published }\end{array}$ & (c) 2019 The Author(s). Published by S. Karger AG, Basel \\
\hline
\end{tabular}

Wang et al.: Residual Renal Function in Peritoneal Dialysis

-23 Chung SH, Heimburger O, Stenvinkel P, Qureshi AR, Lindholm B: Association between residual renal function, inflammation and patient survival in new peritoneal dialysis patients. Nephrol Dial Transplant 2003;18:590-597.

24 Rumpsfeld M, McDonald SP, Johnson DW: Peritoneal small solute clearance is nonlinearly related to patient survival in the australian and new zealand peritoneal dialysis patient populations. Perit Dial Int 2009;29:637-646.

-25 Park JT, Kim DK, Chang TI, Kim HW, Chang JH, Park SY, Kim E, Kang SW, Han DS, Yoo TH: Uric acid is associated with the rate of residual renal function decline in peritoneal dialysis patients. Nephrol Dial Transplant 2009;24:3520-3525.

-26 Hsieh YP, Yang Y, Chang CC, Kor CT, Wen YK, Chiu PF, Lin CC: U-shaped relationship between uric acid and residual renal function decline in continuous ambulatory peritoneal dialysis patients. Nephrology (Carlton) 2017;22:427-435.

27 Maiorca R, Brunori G, Zubani R, Cancarini GC, Manili L, Camerini C, Movilli E, Pola A, d'Avolio G, Gelatti U: Predictive value of dialysis adequacy and nutritional indices for mortality and morbidity in CAPD and HD patients. A longitudinal study. Nephrol Dial Transplant 1995;10:2295-2305.

28 Rocco M, Soucie JM, Pastan S, McClellan WM: Peritoneal dialysis adequacy and risk of death. Kidney Int 2000;58:446-457.

29 Chung SH, Heimbürger O, Stenvinkel P, Bergström J, Lindholm B: Association between inflammation and changes in residual renal function and peritoneal transport rate during the first year of dialysis. Nephrol Dial Transplant 2001;16:2240-2245.

-30 Williams JD, Craig KJ, Topley N, Von Ruhland C, Fallon M, Newman GR, Mackenzie RK, Williams GT; Peritoneal Biopsy Study Group: Morphologic changes in the peritoneal membrane of patients with renal disease. J Am Soc Nephrol 2002;13:470-479.

-31 Van Biesen W, Lameire N, Verbeke F, Vanholder R: Residual renal function and volume status in peritoneal dialysis patients: A conflict of interest? J Nephrol 2008;21:299-304.

-32 Wang AY, Lai KN: The importance of residual renal function in dialysis patients. Kidney Int 2006;69:17261732.

33 Raimann JG, Kitzler TM, Levin NW: Factors affecting loss of residual renal function(s) in dialysis. Contrib Nephrol 2012;178:150-156.

34 Pulliam J, Li NC, Maddux F, Hakim R, Finkelstein FO, Lacson E Jr: First-year outcomes of incident peritoneal dialysis patients in the united states. Am J Kidney Dis 2014;64:761-769.

-35 Fried L, Hebah N, Finkelstein F, Piraino B: Association of Kt/V and creatinine clearance with outcomes in anuric peritoneal dialysis patients. Am J Kidney Dis 2008;52:1122-1130.

-36 Huang JW, Lien YC, Yang CY, Liu KL, Fang CC, Wu CK, Lee JK, Wu HY, Chiang CK, Cheng HT, Yen CJ, Hung KY: High peritoneal Kt/V and peritonitis rates are associated with peritoneal calcification. PLoS One 2013;8:e71636. 